\title{
RESEARCH
}

Open Access

\section{Early life adversity and health inequality: a dual interaction model}

\author{
Zhilei Shi ${ }^{{ }^{*}}$ id and Cary Wu ${ }^{2}$
}

\author{
* Correspondence: zlshi2011@zuel. \\ edu.cn \\ ${ }^{1}$ Research Center of Population and \\ Health, Zhongnan University of \\ Economic and Law, 182\# Nanhu \\ Avenue, East Lake High-tech \\ Development Zone, Wuhan 430073, \\ People's Republic of China \\ Full list of author information is \\ available at the end of the article
}

\begin{abstract}
This article examines the impact of early life adversity on health inequality from a life course perspective. We develop a dual interaction model that considers how both the frequency as well as the duration of early life adversity might shape an individual's health. Analyzing data from the China Health and Retirement Longitudinal Study (CHARLS, 2011-2014), we show that not only does early life adversity have a direct effect on an individual's health, but throughout the life course it also produces cumulative disadvantages through worsening the individual's life conditions such as less education, lower social-economic status, and less job security. The combination of the frequency of adversity experience and the length of exposure creates an exponential effect on poor health, contributing to the persistence of health inequality in contemporary Chinese society.

Keywords: Early-life misfortune, Life-course theory, Cumulative disadvantage, Health inequality, Time effect
\end{abstract}

\section{Introduction}

Health inequality is an important dimension of social inequality. While the overall health of humankind has dramatically improved since the end of the World War II, during the time health inequalities among different individuals, groups, and countries have also become more widespread (Smith and Morris 1994; Levine et al. 2015). Explaining the rising health inequality, scholars have thus far taken two different approaches. On one hand, an individual approach views the differences in people's health status as a result of the differences in individual-level characteristics such as genetic inheritance, socioeconomic status, gender, race, and ethnicity (Barker 1990, 1998; Blackwell et al. 2001; Currie 2011). On the other hand, a structural approach stresses the role of macro-level factors in shaping people's health that include, for example, the market, institutional governance, the welfare redistribution system, as well as the neighborhood context (Grundy and Sloggett 2003; Elo 2009; Wang 2011; Jiao 2016; Fu et al. 2018). These two approaches have been complementary to each other in our understandings toward health inequality. However, they have both relied on single-time- 
point factors to explain health inequality, overlooking the dynamic process of health acquisition and change (Baert 1992).

Time is critical to understanding the social world. In social analysis, time is always social time (Giddens 1984), and we can only possibly acquire an understanding of the nature of social events by grasping the timing or timeliness of the events (see also Foucault 2012). On one hand, time embedded in social interaction is the product of social construction; on the other hand, time is the result and medium of social operation that reflects, regulates, and arranges everyday life (Giddens 1984). The present is partially creating the future, so that the before-and-after of time constitutes a causal connection (Baert 1992). In human life, the interconnectedness of experience events is embodied. Past experiences are the basis of future events, and past experiences need to be maintained and continued by present and future events.

Hence, it is time to take time seriously. In fact, the more recently developed life course theory has systematically incorporated the concept of time into social and empirical studies. Instead of taking a synchronic approach, the life course theory relies on diachronic analysis and process analysis as methodological strategies to study the interaction process between individuals and the social world while taking into account the differences in such interaction across different points in time (Elder 1998). From the life course perspective, early in life during an individual's childhood or adolescence is a critical period of time where the effects of family environment and socialization are most significant. Accordingly, from the life course perspective, it is imperative to consider how early life adversity experiences might shape people's health status later in life.

In China, the profound social and economic changes that have taken place over the past 40 years have had a tremendous impact on traditional Chinese family functions and patterns. Family stability and traditional functions have rapidly weakened with the emergence of single-parent families and dysfunctional families (Hu and Peng 2015). A dysfunctional family, especially parents' negligence of duty, not only affects children's physical and mental health, academic performance, and future development throughout their life, it also leads to bad behaviors for the children within the family and brings serious social problems (Xu et al. 2008). Current studies on how early family life might affect people's health status come mainly from scholars in the fields of biomedicine and public health (e.g., Dong et al. 2004; Miller et al. 2011; Chen Jingqi 2006). Few studies have considered the causal effect and internal mechanism of the impact of early life adversity on the health status of adults from a sociological perspective. However, to gain a deeper understanding of social inequality, it is important to take a sociological perspective and specifically consider how early life adversity leads to cumulative disadvantage and the generation of health inequality from a life course perspective. Essentially, early life adversity reflects the exogenous influence brought about by the original family environment. Therefore, to research the formation mechanism of health inequality, there is a need to shift the focus from the current socioeconomic factors to the upstream of people's life course. In other words, it is necessary to bring the concept of time into the study of health inequality.

In this article, we examine the impact of early life adversity on health inequality from a life course perspective. We develop a dual interaction model that considers the effects of both the frequency and the duration of early life adversity on processes of cumulative disadvantage and the generation of health inequality. To illustrate this model, we use 
data from the China Health and Retirement Longitudinal Survey (CHARLS, 2011-2014). We find that not only does early life adversity yield a direct effect on an individual's health, but throughout the life course, it also produces a cumulative effect by worsening the individual's life conditions such as less education, lower social-economic status, and less job security. Further, we show that the combination of the counts of adversity experience and the length of exposure creates an exponential effect on individuals' poor health. The dual interaction between the counts and the duration of early life adversity contributes to the persistence of health inequality in contemporary Chinese society.

\section{Life course, cumulative disadvantage, and health: a theoretical review} Health inequality through the life course perspective: the time effect

In recent decades, life course theory has become an important analytical framework for the study of the effects of structural, social, and cultural factors on individual health (Elder 1998). Compared with other research methods and theories, the innovation and vitality of life course theory are embodied in its deep analysis of time effects. George (2014) summarized four different time-effect hypotheses commonly adopted in life course health research. The first hypothesis is the duration of exposure. That is, the longer a person experiences an event, the more likely the event is to produce a specific outcome. Even with the same length of experience, the effects of exposure to different risks or protective factors on health are significantly different. The second hypothesis is the time sequence. This means that different time sequences or age periods during which different life experiences and important events occur will have different effects on individual health. The third hypothesis is the effect of the critical period. That is, if a specific development task is not completed at the appropriate age, a series of subsequent events will be postponed, and thus, many opportunities will not appear. The fourth hypothesis is the turning point or milestone effect. That is, the occurrence of some important events may change the original development trajectory of individuals or turn in a completely different direction of development than previously expected (George 2014).

From the life course perspective, the latest research progress on influencing factors of health inequality is mainly reflected in two aspects. One aspect is to attach importance to the long-term impact of early life factors by tracing the origin of health inequality along the time axis to the upstream of the life course. An increasing number of scholars have recognized that early life experience is the basis of life cycle development or that childhood is the starting point of many diseases; i.e., many health changes in adulthood may have taken root decades ago (Warren 2016). Early life adversity, ranging from low birth weight to experiencing abuse or economic deprivation, can have a persistent negative impact on post-adulthood health (Levine et al. 2015; Friedman et al. 2015; Sonderskov and Thisted 2014). The second aspect is to pay attention to the long-term investigation of the influencing factors of health inequality. An increasing number of scholars have tried to describe the impact trajectory of age-related socioeconomic factors on health by integrating information from decades of life (Montez and Hayward 2014).

Two distinct hypotheses are extended from the above two perspectives. One hypothesis is the social origin hypothesis, which holds that early life adversity has a persistent negative impact on health. Regardless of how social and economic status changes after 
childhood, this impact will not be offset. The other hypothesis is the development interference hypothesis, which holds that adult experiences, such as resource acquisition in education and occupational status, have an important regulating effect on early health and can even offset the negative impacts of early age adversity. Especially in adulthood, the rise of social and economic status can form a protective effect, thereby helping individuals to have better health status (Ferraro et al. 2016).

Existing studies have not yet agreed on how early life adversity indirectly affects health through experiences or resources in adulthood. Some scholars believe that compared with short-term poverty or intermittent poverty, experiencing long-term poverty has a more serious negative impact on mental health (Evans and Kim 2007). Studies by Jennifer Montez and Mark Hayward found that early life adversity increases disability and mortality in adulthood and that higher education does not mitigate the impact of early life adversity (Montez and Hayward 2014). Kenneth Ferraro and his colleagues Ferraro et al. (2016) find that experiencing childhood poverty and abuse not only has a direct impact on childhood health but also leads to lower socioeconomic status and unhealthy lifestyles in adulthood, which has a lasting negative impact on adult health. Over time, health inequality will become increasingly larger. In contrast, some scholars believe that early life poverty leads to health inequality in adulthood but that the duration of poverty is not directly related to the subsequent changes in health trajectory (Mcdonough et al. 2005). In general, existing studies still fail to explain what cumulative process the formation mechanism of health inequality has across the whole life course. In this paper, we use the theory of cumulative disadvantage to further address the controversy between the social origin hypothesis and the development interference hypothesis.

\section{Early life adversity, cumulated disadvantage, and health inequality}

A core issue to be addressed in life-course-based health research is how early life experiences affect health inequality decades later (Ferraro et al. 2016). In recent years, scholars have begun to turn their attention to the systematic process that produces internal inequality in the life course. They have combined life course theory with cumulative advantage/disadvantage theory, thereby emphasizing how early life adversity and events make people face high risks, how beneficial experiences create opportunities, how the interaction between these two processes leads to a specific process of inequality, and how the impact on individual's different development trajectories occurs along with increasing age (Dannefer 2003).

Cumulative advantage/disadvantage theory was first proposed by Merton to describe the Matthew effect of career stratification in the scientific community. The theory holds that the repayment of scientists' early career performance increases over time, which means that achievements and prestige in the early career period directly lead to greater success later (Merton 1968). Cumulative advantage/disadvantage theory is widely used in many fields of social science. Generally, occupational stratification studies focus on the process of cumulative advantage, while studies on health inequality or racial inequality are mainly based on the process of cumulative disadvantage due to its necessity of focusing on what outcome will be caused by being in a disadvantaged status or experiencing adversity (Diprete and Eirich 2006). Based on the theme of this paper, this theory is collectively referred to as the theory of cumulative disadvantage in the latter 
part of this paper. The cumulative process of health inequality is generally described along with time changes, i.e., the initial advantages or disadvantages associated with a structural location that continually accumulate throughout the life course and lead to the systematic differentiation of the health status of different individuals or groups (Dannefer 2003). We can regard health as a form of life course capital that can be maintained or consumed at different speeds over time. The change in health capital depends mainly on the resources that people can obtain, the strategies people can adopt, and the opportunities that they face (Willson et al. 2007).

The research on how the cumulative disadvantage process of early life adversity affects adult health is mainly carried out from three dimensions: risk, resource, and behavior selection. First, early life experiences can create opportunities or obstacles for future life. For example, early family poverty increases the likelihood of experiencing risks, hazards, or negative events during an individual's growth (Ferraro and Shippee 2009). Second, early life experiences can affect the path of personal development and obtainable resources. Early life adversity can hinder people's access to education and career opportunities and reduce their probability of achieving higher socioeconomic status in the future (Schafer et al. 2013). Early life disadvantages increase the likelihood of future exposure to risk or of experiencing a life of hardship, but resources help people to respond effectively to these risks. Third, early life experiences can affect adolescent behavioral responses and adulthood lifestyle choices. Early life adversity, for example, increases the risk of unhealthy habits such as smoking (Lloyd and Taylor 2006), alcohol dependence (Lloyd and Turner 2008), and obesity (Greenfield and Marks 2009), which in turn have consistent negative impacts on health.

\section{Types, duration of early life adversity, and health inequality: a dual cumulative disadvantage model}

There has been considerable controversy about the definition of early life adversity. In this study, we draw on the concept of stress put forward by Sheldon Cohen and his colleagues, and consider an adversity experience to be when the occurrence of an event is not controlled by personal desire and brings psychological threats and stress to an individual (Cohen et al. 1995). The concept of stress emphasizes the time dimension of adversity experiences, that is, the persistence of stress events exposed to uncontrollable status and then transformed into a lasting experience and memory. Therefore, in this paper, we focus on the events or experiences that cause severe and long-term stress. At present, academia mainly adopts two methods to measure early life adversity. One method is to examine a single event experienced in early life, such as family socioeconomic status in childhood, the divorce of one's parents, the death of one's parents (Mclanahan et al. 2013), emotional or physical abuse (Dong et al. 2004), and physical health status in childhood (Blackwell et al. 2001). The analysis of a single problem can help us to understand the long-term impact of an event or an experience. However, it is easy to overestimate the impact of one experience while overlooking the multiple or joint effects of different experiences (Pearlin et al. 2005). The second method is to examine the various early life experiences, emphasizing the influential effect of different types of experiences. There are many types of early life adversities, but the existing research related to the health status of adults focuses on two main types: family poverty and parental abuse (Miller et al. 2011). Aiming at the purpose of this study, our strategy 
is to use a large number of retrospective early life experiences provided by China Health and Retirement Logitudinal Survey data to accumulate a variety of adversity events experienced by respondents to investigate the impact of the accumulation of the various types of early life adversities on adult health. This strategy aggregates a variety of adversity events and helps to capture the "cumulative stress of multiple traumas" (Turner and Lloyd 1995).

There are two explanatory models for the impact mechanism of early life adversity on the health of adulthood. One is the model of early life adversity exposure in biomedicine. It is believed that exposure to adversity events in early life will have a longterm impact on health and will have different influential effects on health according to the type, duration, frequency, and severity of the events and the coping strategies (Dong et al. 2004). Although these studies have realized that different types of early life experiences can lead to different levels of health status, they lack explanations for the evolution and mechanism of this effect throughout the life cycle; that is, how and why early life adversity only brings about high-low changes in the intercept of health in later years (as shown in Fig. 1a). The second one is the process cumulative disadvantage model in sociology, which believes that the accumulation of early life adversity will form an accumulative process of stress conduction, such as the reduction of education and employment opportunities and the decline of social and economic status, leading to the continuous expansion of health inequality. However, researchers generally believe that the effects of early life adversity and those of adversity continuously accumulated in adulthood are consistent. In other words, adversity events in early life not only bring about high-low changes in the intercept of adult health but also form the process of continuous accumulation in the course of adulthood (positive slope), and this accumulation is not affected by the degrees of adversity in early life (the slope is consistent, as shown in Fig. 1b).

The accumulation of risk and resources in adulthood is the key to the formation of health inequality. However, previous studies have neglected that the environment and experiences in early life are also important parts of the accumulation process. The trajectory of the life course is influenced by risks, available resources, and strategic behavioral choices throughout the life cycle (Ferraro and Shippee 2009). Early life adversity affects health inequality in adulthood through the dual cumulative disadvantage. That is, along the time axis of the life course, the process of cumulative disadvantage can be divided into the stress accumulation of event occurrence and the process accumulation of stress conduction. The stress accumulation of events refers to the persistent accumulation of early life adversity that will increase the pressure difference of the initial disadvantage in the life course. The greater the initial pressure difference is, the higher the impact of this adversity experience is on later health. There are two dimensions in the stress accumulation of events occurrence. The first dimension is the accumulation of the types of adversity experiences, such as poverty in childhood, frequent quarrels between one's parents, and bullying by neighboring children, which indicate three types of experienced misfortunate events. The second dimension is the accumulation of the duration of the same event, such as poverty in early life-lasting ten years, and the impact and stress brought about by this adversity experience that continues to accumulate. The accumulation of adversity events in early life can lead to changes in health intercepts in later life by continuously accumulating across the life course of adulthood, 


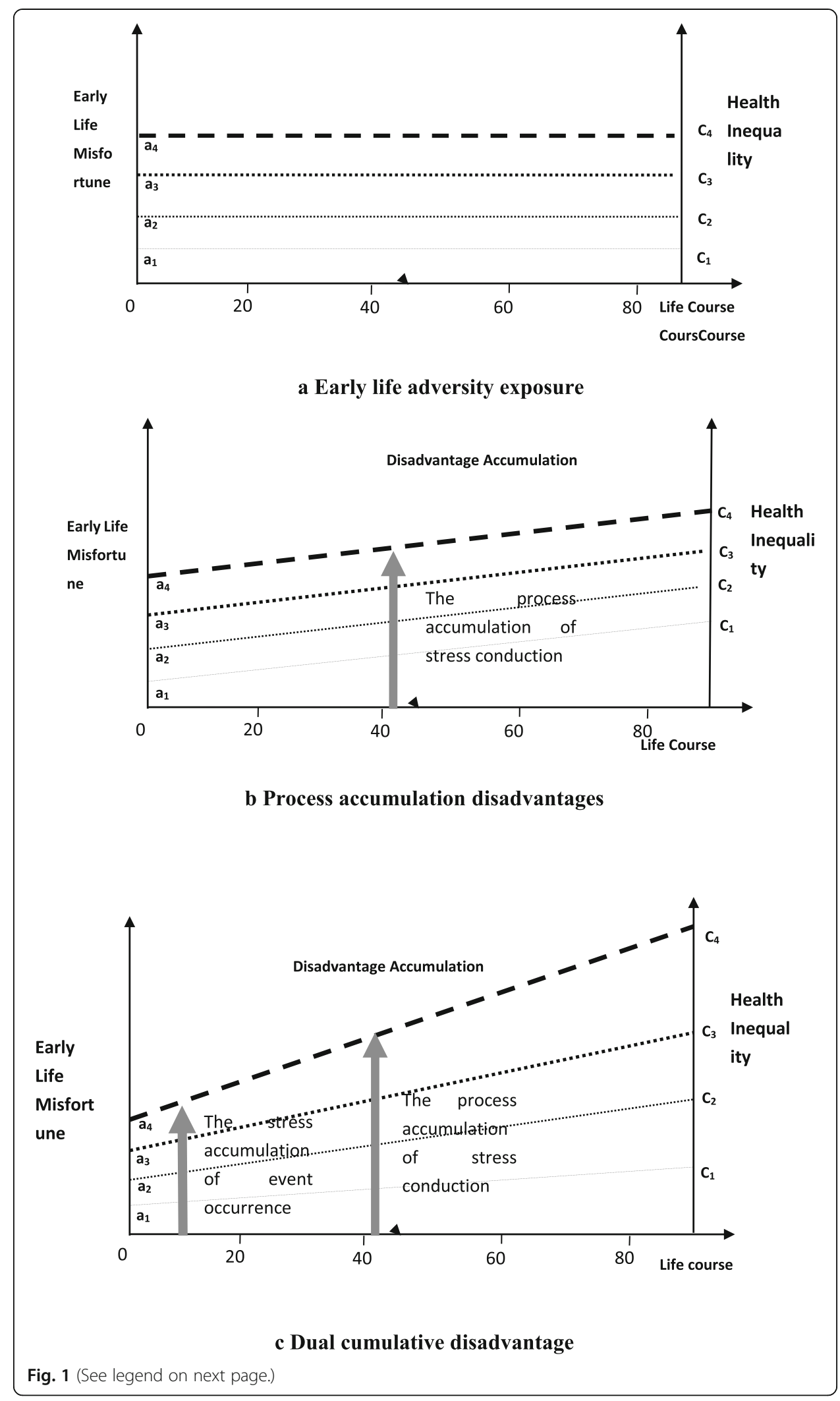


(See figure on previous page.)

Fig. 1 The internal mechanisms by which early life adversity leads to health inequalities. Note: a1-a4 represents the accumulation of types or the duration of early life adversity; c1-c4 represents the disadvantage accumulation line of the types or duration of early life adversity; and the four lines are gradually bolder, indicating the accumulation of disadvantage. The gradient between C1 and C4 represents the widening of health inequalities in adulthood caused by early-life adversity

and the overall degree of accumulation can also be affected by the degree of accumulation of adversity events in one's early life (slope change, as shown in Fig. 1c).

The cumulative process of stress conduction, i.e., early life adversity, leads to other developmental disadvantages in the process of growth, such as the loss of education and employment opportunities, which further widens the initial inequality. Similarly, the higher the difference in the cumulative pressure generated by the event occurrence is, the higher the impact on new experiences or events that occur in the stress conduction. For example, the longer the poverty experienced in early life, the fewer opportunities for higher education or professional status occur in the future, and the accumulation of resources (such as savings) in the process of growth will be reduced accordingly. The reduction of resources in adulthood will further strengthen the accumulation path of early life adversity, thus making it difficult for people to overcome adversity (Ferraro and Kelley-Moore 2003). Therefore, this paper proposes the following four parallel hypotheses about dual cumulative disadvantage:

Hypothesis 1a: The greater the variety of adversity events experienced in early life is, the worse the health condition in adulthood.

Hypothesis 1b: The greater the variety of adversity events experienced in early life is, the higher the impact on risk accumulation and development interference in the growth process.

Hypothesis 2a: The longer the duration of one adversity event in early life is, the worse the health condition in adulthood.

Hypothesis $2 \mathrm{~b}$ : The longer the duration of one adversity event in early life is, the higher the impact on risk accumulation and development interference in the growth process.

Another key point of academic debate is how cumulative disadvantage changes with age. According to the cumulative disadvantage theory, it can be expected that the health inequality brought about by early life adversity will show a tendency to expand with age. This description only illustrates the changing trend of inequality; the cumulative disadvantage is the power of influence. From the perspective of the dual cumulative disadvantage model, from childhood to adulthood, health inequality is further strengthened under the influence of factors of process accumulation; from adulthood to old age, the influence of early life adversity may be weakened. On the one hand, people will adapt to and adjust their early disadvantages; on the other hand, physiological aging during this period will also interfere with the influence of these factors. Therefore, this paper proposes the following two competitive research hypotheses:

Hypothesis 3a: Early life adversity can adversely affect the health condition in adulthood, and health inequality continues to expand over time. 
Hypothesis 3b: Early life adversity and the expansion of health inequality show an inverted U-shape; that is, the accumulation of the disadvantage of early life adversity shows a trend of first expanding and then shrinking over time.

Across the whole life course, the cumulative inequality mechanism of early life adversity affecting the health status of adults is mainly realized through the following channels. The first is direct health loss. Childhood experiences have a direct impact on people's early health. Adversity experiences such as starvation and suffering abuse in childhood can directly lead to loss of health (Barker 1990). In addition, health status in early life is the basis of resisting disease invasion and healthy evolution in people's later life course (Barker 1998). Second, interference and health risks should be developed. An unfortunate childhood experience will reduce one's access to university education, and illiteracy or a low educational level will reduce the likelihood of obtaining a better job and higher social status. Besides, low socioeconomic status in adulthood is positively correlated with poor health, especially with the increased risk of cardiovascular disease and mortality (Goodwin et al. 2003). Meanwhile, poorer jobs mean more health risks and a lack of health insurance, thereby making it difficult to obtain better health care (Ferrie et al. 2003). The third channel is that of negative emotions. Children who grow up under pressure will develop and maintain negative beliefs about others, such as hostility and distrust (Drukker et al. 2003). Vigilance and distrust toward others develop the starting point of the accumulation cycle of self-awareness, which ultimately leads to poor social relationships. These characteristics lead people to perceive and participate in society in a way that causes conflict and rejection, which prevents them from obtaining support and warmth from others and makes it possible to experience more hardships and isolation in life (Miller et al. 2011). Therefore, this paper proposes the following three parallel hypotheses:

Hypothesis 4a: Compared with someone who has no early life adversity experiences, people who experienced early life adversity are more likely to have poor health in early life, and this difference partly explains the difference in their later health status. Hypothesis 4b: Compared with someone who has no early life adversity experiences, people who experienced early life adversity are more likely to suffer development interference (such as educational opportunities, occupational status) during their growth, and this difference partly explains the difference in their later health status. Hypothesis 4c: Compared with someone who has no early life adversity experiences, people who experienced early life adversity are more likely to develop depression in adulthood, and this difference partly explains the difference in their later health status.

\section{Empirical strategies: data, methods, and models}

\section{Empirical strategies}

Consider the following basic equation that represents the idea that early life experience affects health stock:

$$
H_{\mathrm{i}}=\alpha_{0}+\alpha_{1} M_{\mathrm{i}}+\alpha_{\mathrm{\tau}} X_{\mathrm{i}}+\mu_{\mathrm{i}}
$$

In the equation, $H_{\mathrm{i}}$ is the current health stock of individual $\mathrm{i}, M_{\mathrm{i}}$ is the adversity experience variable from his or her early life, $X_{\mathrm{i}}$ represents the other control variable(s), 
and $\mu_{\mathrm{i}}$ is the stochastic disturbance. Combined with the dual cumulative disadvantage proposed in the above part of the theoretical analysis, we use two kinds of early life adversity to replace $M_{\mathrm{i}}: M_{1}$ is the cumulative types of early life adversities, and $\mathrm{M}_{2}$ is the cumulative duration of early life poverty experiences.

To obtain unbiased and consistent estimation results, the endogenous problem of core variables and sample selection in the model must be addressed. There are three main sources of endogenous variables. The first is reverse causality. The core independent variable of this study is the cumulative adversity experience of the respondents between the ages of 0 and 17, while the health variable is the current health status of the respondents between the ages of 40 and 80 . The current state of health should not affect the experience of decades ago; thus, reverse causality can be avoided. The second is the measurement error problem. To improve the accuracy of the health variables, we focus on the probability of self-rated poor health. Adults may have large measurement errors when reporting their childhood experiences; therefore, we use Montez and Hayward's (2014) strategies and define early life experiences as those that occurred between the ages of 0 and 17 years, while examining childhood and adolescent experiences. The third is missing variables, which are important issues to be addressed in a study of the impact of early life experience on health (Ferraro et al. 2016).

Previous studies have shown that regression models of early life experience and health are often disturbed by unobservable factors, such as parental genetic inheritance, health endowment, and personality preferences. These factors also affect the respondents' early life experience and current health status (Frijters and Ulker 2008). In the social sciences, genetic inheritance and potential personality preferences are difficult to measure. We use the respondents' original family characteristics as proxy variables, including parents' educational level, whether the birthplace was rural or urban, and the number of siblings. On the one hand, the respondents' initial health endowment reflects their endurance capability toward adversity experiences; on the other hand, it is also the basis of future health evolution. In the model, the gender of the respondents and the longevity of their mothers were taken as proxy variables of early health endowment. Previous studies have found that the influence of early life experience on health status decreases dramatically when early health status is controlled (Adams et al. 2003). In the basic model, we focus on controlling two groups of variables, namely, the parent characteristics from the respondent's original family $\left(F_{\mathrm{i}}\right)$ and the original health endowment $\left(E_{\mathrm{i}}\right)$. The estimation equation (1) is expanded as follows:

$$
H_{\mathrm{i}}=\alpha_{0}+\alpha_{1} M_{\mathrm{i}}+\alpha_{2} F_{\mathrm{i}}+\alpha_{3} E_{\mathrm{i}}+\mu_{\mathrm{i}}
$$

The main source of sample selection is death selectivity caused by health inequality. One view is that an individual living in a harsh childhood environment has hereditary or congenital traits that enhance his or her survival and health throughout the life cycle (Mu and Zhang 2011). For example, famine survivors who experience extreme difficulties in childhood are less likely to develop disabilities in adulthood. It is also argued that early life adversity leads to a decline in people's health; as age increases, the mortality rate of individuals who have poor health is higher (Willson et al. 2007). To solve this problem, this study uses the data of the China health and pension tracking survey from 2011, 2013, and 2014 to investigate whether the health inequality caused by the early life adversity of individuals who are in the same birth cohort was widening in 2011- 
2013. The specific estimation methods are as follows: to investigate the evolution of the coefficient of the impact of early life adversity on health in the 40-80 age group both before and after the inflection point, to select two groups from the same age cohort from the panel data in 2011 and 2013, and to estimate the changing trend of the impact of early life adversity on health with age growth.

Since there are 23 years between the age of 17 and the surveyed age of 40 , this range provides us with the possibility to examine the mechanism of the impact of long-term poverty on health. Equation 2 estimates the comprehensive effects of early life adversity on adulthood health, including the direct impact of early life adversity on adult health and the indirect impact of early life adversity on health through the intervening variables of the stress conduction process. Since the traditional channel impact decomposition method is only applicable to linear models, in this paper, we use the decomposition method developed by Kristian Karson, Holm, and Breen (KHB method) to estimate the mediation effect (Kohler et al. 2011). This method can not only decompose the regression results of a nonlinear binary probability model but also allow a variety of independent variables and mediating variables to be introduced into the model together.

The main function of the intermediary analysis is to test the three hypotheses of the influence mechanism proposed above. The first group is the health status of early life, and two indicators-whether they had a serious illness before 15 years of age and their selfrated health status before 15 years of age-are selected to reflect the direct health loss caused by early-life adversity. The second group consists of education, occupation, and socioeconomic status, which mainly reflects the impact on personal development. Social and economic status is measured by two indicators, namely, the attributes of the current residence level and the self-evaluated socioeconomic status. This group also includes cumulative health risks that are measured by disability. The third group is depression, which reflects the influence of early life adversity on the individual social initiative.

\section{Data introduction}

The data used in this study are from the China Health and Retirement Longitudinal Study conducted by the National School of Development of Peking University. The national baseline survey data were collected in 2011, with a total of 17,707 respondents, and the second follow-up survey was conducted in 2013 , with 15,678 people being successfully followed up with; in 2014, the respondents' life courses were retrospectively investigated.

According to the research needs, the data are screened according to the following rules: excluding samples older than 80 years old and less than 40 years old, and excluding samples with missing interview information for variables introduced into the model. Because many variables are used, and there are different types of missing variables in the different models, we use 9701 valid samples from the core model as the basic samples for data analysis. Limited by the length of the current study, the variable description statistics are not listed herein. Interested readers can contact the author for more information.

\section{Main variables}

Result variables: self-rated health status

Compared with single objective indicators reflecting illness status, self-rated health status can better reflect people's comprehensive health status. Many studies have shown that self- 
rated health status is highly correlated with more "objective" indicators (such as doctor's diagnosis and morbidity) after controlling for factors such as family medical history and health behavior (Jylha 2009). Further studies have shown that respondents who self-rate as having "bad" health are more accurate in measuring health status and can effectively predict acute and chronic mortality (Burstrom and Fredlund). In this study, "bad" self-rated health was set as the dependent variable, the answers of "bad" and "very bad" were coded as 1 , and the answers of "excellent," "very good," "good," and "average" were coded as 0.

\section{Major predictor variables: early life adversity}

This study demonstrates the accumulation of stress in early life from two dimensions. The first dimension is the accumulation of the type of adversity, which is measured by the total score of eight kinds of adversity experiences. The principles for selecting the specific indicators of adversity experiences are as follows: (1) drawing on lessons for methods of selecting indicators from previous literature (Schafer et al. 2011) and focusing on exogenous and irreversible events or experiences; and (2) combining the specific situation of Chinese families with the CHRLS questions of early life experience by choosing from four aspects: low-income families, problem families, family disintegration, and exposure to abuse. Specifically, these experiences include long-term experience of starvation, relative poverty, long-term illness of parents in bed, severe disability or mental disorders, parents often quarreled, parents divorced, parents died, was bullied by neighboring children, and was often beaten by parents. We asked the respondents about all the experiences one by one, and we coded the answer "yes" as 1 and the answer "no" as 0; then, we summed them up to construct an index consisting of values between 0 and 8 . Considering that the number of respondents with a proportion of five or more adversity experiences is very small, we coded those with four or more adversity experiences as 4 . The second dimension is the cumulative duration of the same event, which is measured by the duration of starvation experienced between the ages of 0 and 17. In the classical literature of poverty studies, scholars typically decide to use the ability to obtain adequate food (hunger) as a measure of absolute poverty (Sen 1981; Berg et al. 2016). If people were suffering from hunger for a period of time, then it can be concluded that they were living in poverty during that period or even for a long time (Sen 1983). Drawing on the existing research strategies and considering the characteristics of the rural poor in China, we used the experience of suffering from starvation during a certain period as a measure of long-term poverty. We further divided the ages of 0-17 into three stages and investigated whether the interviewees had experiences with hunger during the ages of 0-5, 6-12, and/or 13-17.

\section{Control variables}

Three modules are introduced into the model, namely, the initial health endowment, the characteristics of the original family, and the basic demographic characteristics. Initial health endowment was measured by the gender of the interviewee and whether his/ her mother was long-lived. The original family characteristics include whether the respondent's birthplace was urban or rural, whether their father is literate, whether their mother is literate, their father's occupation, and the number of their siblings. The basic demographic characteristics include the age, gender, and marital status of the interviewee. 


\section{The impact of early life adversity on health: a quantitative analysis}

Based on the previously mentioned theoretical analysis and research design, we first use equation (2) to estimate the impact of the types and duration of early life adversity on health and then estimate the time-varying trend of early life adversity on health by dividing the age groups.

The effects of the types and duration of early life adversity on health

\section{Basic estimates}

The core independent variables introduced in model 1 and model 5 of Table 1 are the type of early life adversity and the duration of starvation in one's early life, which are continuous variables. The regression results show that after controlling for factors such as family characteristics and initial health endowment, the type and duration of early life adversity had a significant negative impact on the health status of adults $(p<0.001)$. That is, the more types of early life adversities or the longer the duration of a adversity, the worse the health status of an adult is. The odds ratio calculations show that the probability of self-rated poor health increased by 27.6 percent for every additional type of early life adversity and by 13.5 percent for every additional stage of starvation in early life.

Model 2 and model 6 in Table 1 introduce the type of early life adversity and the duration of starvation in early life into the model in the form of categorical variables. The estimation results show that the coefficient for the influence of the variables presents a gradient increase when the type of early life adversity increases from one to four or more and when the duration of starvation in one's early life increases from one stage to three stages. It can be seen that early life adversity forms the stress accumulation of event occurrence with the increase of the type and duration of events (Table 2).

The health effects of early life adversity differ between urban and rural areas. Although the results of the regression of urban and rural residents show a similar gradient change, compared with urban residents, the increase in the types of early life adversities has a higher impact on the health of rural residents. There was no significant impact on the health of urban residents after experiencing one stage of starvation in early life while experiencing two stages or more produces significant coefficients. However, when starvation was experienced in all three stages, the health coefficient of the urban residents was significantly higher than that of the rural residents.

For someone who has a higher level of education or increasing socioeconomic status, will the impact of early life adversity on health remain stable? We further introduce the interaction terms of early life adversity, education years, and socioeconomic status in equation (2) to examine the moderating effect of level of education and socioeconomic status on early life adversity. The estimation results show that when the level of education and socioeconomic status is low, then the type and duration of early life adversity have a stable negative impact on health, which is significant at the 0.001 statistical level. The estimation results also show that the influence of the type and duration of early life adversity does not diminish with the improvement of education and socioeconomic status. The coefficient of the interaction item of early life adversity and socioeconomic status is not significant, while that of education level is positive and significant at the statistical level of $p=$ 0.05. In other words, even if upward social mobility is achieved throughout the life course, the negative impact of early life adversity on health persists. 
Table 1 Variable introduction and description statistics ( $N=9701)$

\begin{tabular}{|c|c|c|c|c|c|}
\hline Variable & Measurement & $\begin{array}{l}\text { Mean } \\
\text { value }\end{array}$ & $\begin{array}{l}\text { Standard } \\
\text { deviation }\end{array}$ & $\begin{array}{l}\text { Minimum } \\
\text { value }\end{array}$ & $\begin{array}{l}\text { Maximum } \\
\text { value }\end{array}$ \\
\hline $\begin{array}{l}\text { Self-rated } \\
\text { health }\end{array}$ & $\begin{array}{l}\text { The answers of "not good" and "very bad" are } \\
\text { assigned to 1, and the answers of "excellent", "very } \\
\text { good," "good," and "general" are assigned to } 0\end{array}$ & 0.255 & 0.436 & 0 & 1 \\
\hline \multicolumn{6}{|c|}{ The types of early life adversities } \\
\hline 1 type & Experienced 1 type of adversity & 0.315 & 0.465 & 0 & 1 \\
\hline 2 types & Experienced 2 types of adversity & 0.162 & 0.369 & 0 & 1 \\
\hline 3 types & Experienced 3 types of adversity & 0.072 & 0.259 & 0 & 1 \\
\hline$\geq 4$ types & Experienced 4 or more types of adversity & 0.031 & 0.173 & 0 & 1 \\
\hline \multicolumn{6}{|c|}{ Duration of starvation in early life } \\
\hline 1 period & 1 period of starvation & 0.354 & 0.478 & 0 & 1 \\
\hline 2 periods & 2 periods of starvation & 0.161 & 0.368 & 0 & 1 \\
\hline 3 periods & 3 periods of starvation & 0.190 & 0.392 & 0 & 1 \\
\hline Gender & Male $=1$, female $=0$ & 0.477 & 0.500 & 0 & 1 \\
\hline Age & Choose age between $40-80$ & 59.29 & 8.381 & 40 & 80 \\
\hline Marriage & Married $=1$, not married $=0$ & 0.893 & 0.309 & 0 & 1 \\
\hline $\begin{array}{l}\text { Whether } \\
\text { mother lived a } \\
\text { long life }\end{array}$ & Mother's age $>=70$ s $1,<70$ s 0 & 0.742 & 0.438 & 0 & 1 \\
\hline Father literacy & Literacy $=1$, illiteracy $=0$ & 0.460 & 0.498 & 0 & 1 \\
\hline $\begin{array}{l}\text { Mother } \\
\text { literacy }\end{array}$ & Literacy $=1$, illiteracy $=0$ & 0.136 & 0.343 & 0 & 1 \\
\hline Birthplace & Urban $=1$, rural $=0$ & 0.081 & 0.273 & 0 & 1 \\
\hline $\begin{array}{l}\text { Father's } \\
\text { occupation }\end{array}$ & Manager or technician $=1$, ordinary worker $=0$ & 0.165 & 0.371 & 0 & 1 \\
\hline $\begin{array}{l}\text { Number of } \\
\text { siblings }\end{array}$ & $\begin{array}{l}\text { Size of the original family; assign } 12 \text { people or } \\
\text { more to } 12\end{array}$ & 4.053 & 1.897 & 0 & 12 \\
\hline $\begin{array}{l}\text { Serious illness } \\
\text { in early life }\end{array}$ & $\begin{array}{l}\text { Whether seriously sick for over } 1 \text { month before the } \\
\text { age of } 15\end{array}$ & 0.053 & 0.223 & 0 & 1 \\
\hline $\begin{array}{l}\text { Self-rated early } \\
\text { life heath }\end{array}$ & Poor self-rated health $=1$, average, good $=0$ & 0.048 & 0.214 & 0 & 1 \\
\hline Education & Years of education & 5.549 & 4.163 & 0 & 19 \\
\hline Occupation & Non-agricultural employment $=1$, farmer $=0$ & 0.491 & 0.500 & 0 & 1 \\
\hline $\begin{array}{l}\text { Attribute of } \\
\text { residence }\end{array}$ & $\begin{array}{l}\text { Rural assigned to } 0 \text {, central village district assigned } \\
\text { to } 1 \text {, the special district assigned to } 2 \text {, rural-town } \\
\text { fringe zone assigned to } 3 \text {, central town district } \\
\text { assigned to } 4 \text {, rural-urban fringe zone assigned to } \\
5 \text {, and main urban zone assigned to } 6\end{array}$ & 1.654 & 2.241 & 0 & 6 \\
\hline $\begin{array}{l}\text { Relative } \\
\text { economic } \\
\text { status }\end{array}$ & $\begin{array}{l}\text { Compared with the neighborhood, self-rated eco- } \\
\text { nomic status }\end{array}$ & 2.637 & 0.829 & 1 & 5 \\
\hline Disability & Whether respondent is disabled & 0.237 & 0.425 & 0 & 1 \\
\hline $\begin{array}{l}\text { Depressed } \\
\text { mode }\end{array}$ & Using CED-10 depression self-rating scale & 7.821 & 5.761 & 0 & 30 \\
\hline
\end{tabular}

\section{Robustness testing: endogeneity and sample selection}

Considering that most of the interviewees were born circa 1950 and experienced rapid urbanization in China in their early life, their economic and social activities depended heavily on agricultural development. In this paper, we take the frequency of local drought and flood disasters in the 18 years ranging from 0 to 17 years of age as a 
Table 2 Estimated effects of the type and duration of early life adversity on health

\begin{tabular}{|c|c|c|c|c|c|c|c|c|}
\hline & $(1)$ & $(2)$ & (3) & (4) & (5) & (6) & $(7)$ & (8) \\
\hline & $\begin{array}{l}\text { Urban- } \\
\text { rural }\end{array}$ & $\begin{array}{l}\text { Urban- } \\
\text { rural }\end{array}$ & Town & Village & $\begin{array}{l}\text { Urban- } \\
\text { rural }\end{array}$ & $\begin{array}{l}\text { Urban- } \\
\text { rural }\end{array}$ & Town & Village \\
\hline Type of early life adversity & $0.244^{* * *}$ & & & & & & & \\
\hline $\begin{array}{l}\text { Type of early life adversity ( } 0 \text { as } \\
\text { reference) }\end{array}$ & $(0.022)$ & & & & & & & \\
\hline \multirow[t]{2}{*}{ One type } & & $0.232^{* * *}$ & $0.299^{* * *}$ & $0.184^{* * *}$ & & & & \\
\hline & & $(0.058)$ & $(0.103)$ & $(0.071)$ & & & & \\
\hline \multirow[t]{2}{*}{ Two types } & & $0.558^{* * *}$ & $0.593^{* * *}$ & $0.516^{* * *}$ & & & & \\
\hline & & $(0.069)$ & $(0.126)$ & $(0.083)$ & & & & \\
\hline \multirow[t]{2}{*}{ Three types } & & $0.642^{* * *}$ & $0.614 * * *$ & $0.618^{* * *}$ & & & & \\
\hline & & $(0.092)$ & $(0.178)$ & $(0.108)$ & & & & \\
\hline \multirow[t]{2}{*}{ Four types or more } & & $1.000^{* * *}$ & $0.899 * * *$ & $1.001^{* * *}$ & & & & \\
\hline & & $(0.130)$ & $(0.249)$ & $(0.155)$ & & & & \\
\hline \multirow{2}{*}{$\begin{array}{l}\text { Duration of starvation in early } \\
\text { life ( } 0 \text { as reference) }\end{array}$} & & & & & $0.127^{* * *}$ & & & \\
\hline & & & & & $(0.023)$ & & & \\
\hline \multirow[t]{2}{*}{ One period } & & & & & & $0.134^{* *}$ & 0.065 & $0.168^{* *}$ \\
\hline & & & & & & $(0.062)$ & $(0.111)$ & $(0.076)$ \\
\hline \multirow[t]{2}{*}{ Two periods } & & & & & & $0.207^{* * *}$ & $0.241^{*}$ & $0.199^{* *}$ \\
\hline & & & & & & $(0.076)$ & $(0.136)$ & $(0.092)$ \\
\hline \multirow[t]{2}{*}{ Three periods } & & & & & & $0.397^{* * *}$ & $0.517^{* * *}$ & $0.335^{* * *}$ \\
\hline & & & & & & $(0.072)$ & $(0.134)$ & $(0.087)$ \\
\hline \multicolumn{9}{|l|}{ Control variable } \\
\hline Native family characteristics & Y & Y & Y & Y & Y & Y & Y & Y \\
\hline Initial health endowment & Y & Y & Y & Y & Y & Y & Y & Y \\
\hline Demographic characteristics & Y & Y & Y & Y & Y & Y & Y & Y \\
\hline Provincial dummy variable & Y & Y & Y & Y & Y & Y & Y & Y \\
\hline N & 9701 & 9701 & 3522 & 6179 & 9701 & 9701 & 3522 & 6179 \\
\hline$R^{2}$ & 0.045 & 0.045 & 0.043 & 0.045 & 0.037 & 0.038 & 0.038 & 0.036 \\
\hline
\end{tabular}

variable of early life adversity and further weight the drought and flood disasters by the local topographic and geomorphological characteristics. The estimation results of the first-stage regression show that there is no weak instrumental variable problem; the endogeneity test of the second-stage variables has a value of $p>0.74$, and the assumption that early life adversity is an exogenous variable is not rejected. That is, the consistency estimation can be obtained by using general probit regression.

In addition, those who experienced early life adversity may have some characteristics of their own or be affected by unobservable factors. We use the Heckit method to process this sample selection problem. The estimation results show that both the type of early life adversity and the duration of starvation in early life have a positive impact on the probability of self-rated poor health in adulthood and are significant at 0.001 statistical level, indicating that the impact of the sample selection is within the allowable range. 
The age pattern of early life adversity affecting health: an inverted U-shape

We use age-segment regression to test the expansion effect of health inequality. The regression results (Table 3) show that in the 40-80 age group, as age increases, the coefficient of cumulative disadvantage formed by the type and duration of early life adversity increases first and then decreases. So, the inverted U-shaped hypothesis of early life adversity and the expansion of health inequality is confirmed. In terms of age group, for each increase in the type of early life adversity, the probability of poor health self-rated by the respondent is increased by 39.7 percent for the 40-49 age group and by 40.5 percent for the 50-59 age group. At this point, the influence of early life adversity begins to decline, and the probability is increased by 17.4 percent for the 60-69 age group and by 16.8 percent for the 70-80 age group. The effect of the duration of starvation in early life on health also shows an inverted U-shape, and the inflection point occurs around the age of 60 .

To exclude the effect of death selectivity, this study used panel data to examine how the effects of early life adversity on health change over time in a cohort of people of the same age. The estimation results in Table 4 show that for the 50-59 age group, for each increase in the type of early life adversity, the probability self-evaluated poor health by the respondent is increased by 24.4 percent in 2011 and by 36.3 percent in 2013, while for the 60-69 age group, for each increase in the type of early life adversity, the probability of self-evaluated poor health by the respondent is increased by 21.2 percent in 2011 and by 20.2 percent in 2013. The effect of the duration of starvation in early life on health also shows an increasing trend in the 50-59 age group and a decreasing trend in the 60-69 age group. These outcomes fully demonstrate that with an increase in age, the early life adversity and the expansion of the accumulation of disadvantage present an inverted U-shape, and the inflection point occurs around the age of 60.

\section{Interaction process between early life adversity and health inequality in adulthood}

Figs. 2 and 3 describe the interaction between early life adversity and the probability of poor health as age increases. The probability of poor health is based on the estimation results of equation (2). Overall, the probability of self-rated poor health

Table 3 The effects of early life adversity on health: estimated by age group (data year 2013)

\begin{tabular}{|c|c|c|c|c|c|c|c|c|}
\hline & \multicolumn{4}{|c|}{ Number of exposure events } & \multicolumn{4}{|c|}{ Length of exposure } \\
\hline & $\begin{array}{l}\text { Age } 40- \\
49\end{array}$ & $\begin{array}{l}\text { Age 50- } \\
59\end{array}$ & $\begin{array}{l}\text { Age 60- } \\
69\end{array}$ & $\begin{array}{l}\text { Age 70- } \\
80\end{array}$ & $\begin{array}{l}\text { Age } 40- \\
49\end{array}$ & $\begin{array}{l}\text { Age 50- } \\
59\end{array}$ & $\begin{array}{l}\text { Age 60- } \\
69\end{array}$ & $\begin{array}{l}\text { Age } 70- \\
80\end{array}$ \\
\hline \multirow[t]{2}{*}{ Type of early life adversity } & $0.334^{* * *}$ & $0.340^{* * *}$ & $0.160^{* * *}$ & $0.155^{* *}$ & & & & \\
\hline & $(0.066)$ & $(0.037)$ & $(0.036)$ & $(0.061)$ & & & & \\
\hline \multirow{2}{*}{$\begin{array}{l}\text { Duration of early life } \\
\text { starvation }\end{array}$} & & & & & $0.178^{* *}$ & $0.208^{* * *}$ & $0.082^{* *}$ & 0.008 \\
\hline & & & & & $(0.071)$ & $(0.038)$ & $(0.041)$ & $(0.055)$ \\
\hline Control variable & Y & Y & Y & Y & Y & Y & Y & Y \\
\hline$N$ & 1312 & 3792 & 3311 & 1276 & 1312 & 3792 & 3311 & 1276 \\
\hline$R^{2}$ & 0.084 & 0.068 & 0.035 & 0.034 & 0.07 & 0.055 & 0.031 & 0.03 \\
\hline
\end{tabular}

Note: Table 3 is a cross-sectional analysis using data from 2013; Table 4 is a panel data analysis matching the data from 2011 and 2013, with the sample sizes consistent between the 2 years

The model introduces the same control variables, including original family characteristics, initial health endowment, demographic characteristics, and provincial dummy variables

${ }^{*} p<0.1$

${ }^{* *} p<0.05$

${ }^{* * *} p<0.01$; the robust standard errors are in parentheses 
increases with age. This outcome reflects the decline in health caused by the aging of biological attributes. Regardless of whether the respondent had an early life adversity or what kind of adversity they experienced, the decline in health levels brought about by age growth has the same impact on these populations. The change in health level in the 40-54 age group is relatively gentle, but then the risk of self-rated poor health rises rapidly.

In terms of the cumulative impact of early life adversity, in every age group between the ages of 40 and 80, the more types of early life adversities there are or the longer the duration of starvation is, the higher the probability of self-rated poor health, showing a significant gradient effect. For example, in the 46-year-old cohort, the probability of self-rated poor health in the group without early life adversity is 16.08 percent. With the increase in adversity from one type to four types, the probability of self-rated poor health gradually increases from 20.76 to 34.58 percent, an increase of 18.5 percent. At the age of 80 , the probability of the selfassessment of poor health is 28.13 percent in the group without early life adversity and 59.7 percent in the group with four or more types of adversity, which is an increase of 31.57 percent. In addition, experiencing starvation also shows a similar gradient cumulative effect. It can be seen that with the increase of age, as well as with the accumulation of adversity and time, the health inequality between the groups with or without adversity experience continues to expand.

\section{Dual cumulative disadvantage of early life adversity: a mediation analysis}

According to the previously stated theoretical analysis, the systematic differentiation of health status among different individuals or groups caused by early life adversity is realized through the dual cumulative disadvantage during life. In the following, we perform a two-step empirical test. The first step is to estimate the impact of the accumulation of type and duration of early life adversity on early health and education and socioeconomic status in the growth process and to test whether the greater the cumulative

Table 4 The effects of early life adversity on health: estimated by age group (panel data year 2011-2013)

\begin{tabular}{|c|c|c|c|c|c|c|c|c|}
\hline & \multicolumn{4}{|c|}{ Number of exposure events } & \multicolumn{4}{|c|}{ Length of exposure } \\
\hline & \multicolumn{2}{|c|}{ Age 50-59 } & \multicolumn{2}{|c|}{ Age 60-69 } & \multicolumn{2}{|c|}{ Age 50-59 } & \multicolumn{2}{|c|}{ Age 60-69 } \\
\hline & 2011 & 2013 & 2011 & 2013 & 2011 & 2013 & 2011 & 2013 \\
\hline \multirow[t]{2}{*}{ Type of early life adversity } & $0.218^{* * *}$ & $0.310^{* * *}$ & $0.192^{* * *}$ & $0.184^{* * *}$ & & & & \\
\hline & $(0.034)$ & $(0.034)$ & $(0.033)$ & $(0.033)$ & & & & \\
\hline \multirow[t]{2}{*}{ Duration of early life starvation } & & & & & $0.142^{* * *}$ & $0.186^{* * *}$ & $0.0879^{* *}$ & $0.074^{*}$ \\
\hline & & & & & $(0.034)$ & $(0.035)$ & $(0.037)$ & $(0.038)$ \\
\hline Control variables & Y & Y & Y & Y & Y & Y & Y & Y \\
\hline$N$ & 4274 & 4274 & 3727 & 3727 & 4274 & 4274 & 3727 & 3727 \\
\hline$R^{2}$ & 0.050 & 0.061 & 0.039 & 0.038 & 0.045 & 0.050 & 0.033 & 0.032 \\
\hline
\end{tabular}

Note: Table 3 is a cross-sectional analysis using data from 2013; Table 4 is a panel data analysis matching the data from 2011 and 2013, with the sample sizes consistent between the 2 years

The model introduces the same control variables, including original family characteristics, initial health endowment, demographic characteristics, and provincial dummy variables

${ }^{*} p<0.1$

${ }^{* *} p<0.05$

${ }^{* * *} p<0.01$; the robust standard errors are in parentheses 


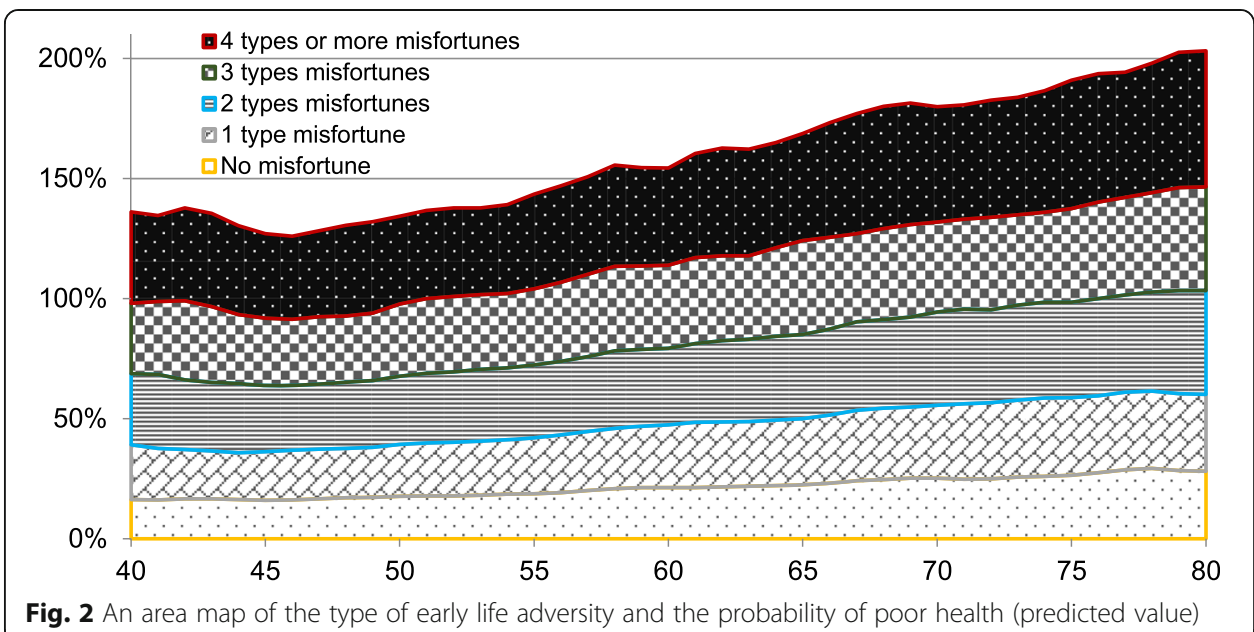

stress of events, the greater the impact on early health status and mediating variables. The second step is using the recently popular mediating effect decomposition method (KHB method) to estimate the decomposition effect of mediating variables on early life adversity and to test whether early life adversity brings about new disadvantages that indirectly affect health.

The estimation results show that both the type of early life adversity and the cumulative duration of starvation in early life have significant negative impacts on mediating variables such as early health, personal development, health risks, and negative emotions. The more the cumulative types are or the longer the duration of adversity experiences is, the higher the impact on these mediating variables. For example, compared with the group without early life adversity, for each additional type of adversity experienced in early life, the probability of serious illness before the age of 17 increased by 33.9 percent, and the average length of education decreased by 0.54 years, which increased the depression index after adulthood by 3.47 percent. Starvation in early life

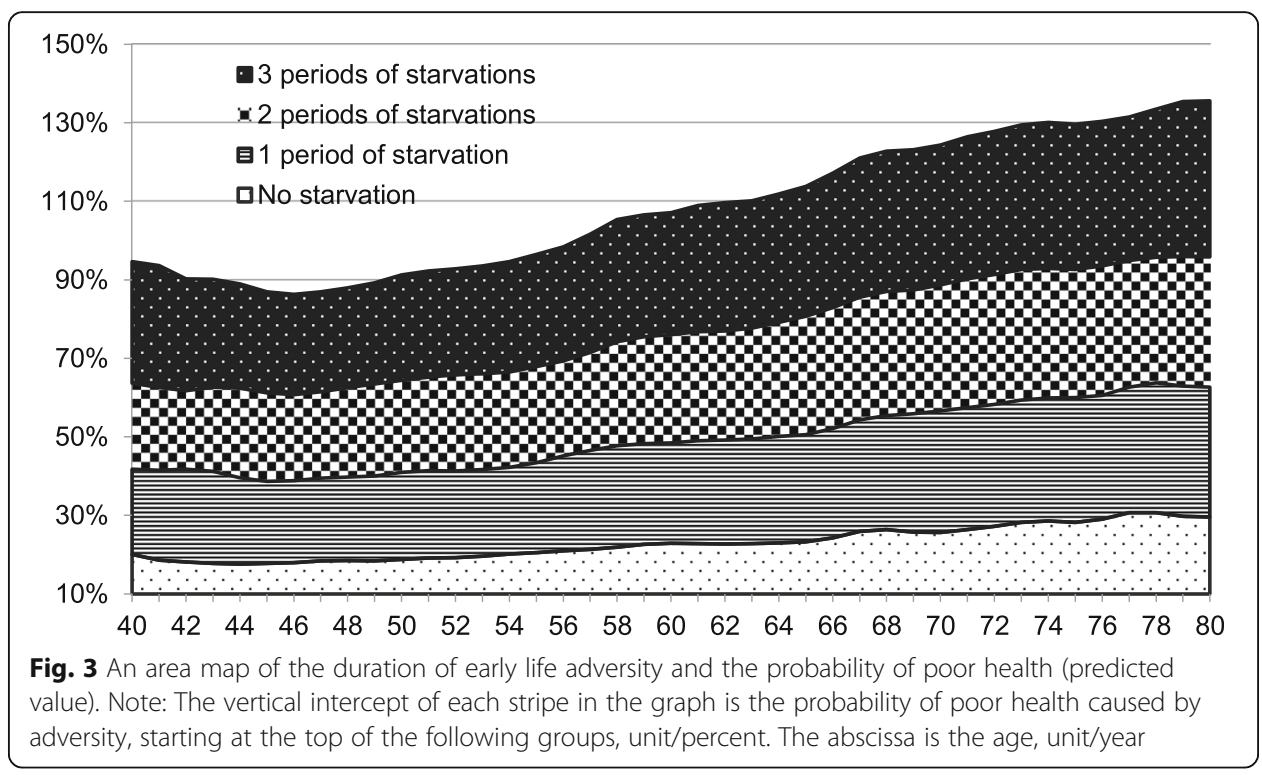


has a similar effect. Hypotheses $2 \mathrm{a}$ and $2 \mathrm{~b}$ that were proposed in the theoretical analysis are thereby confirmed.

Early life adversity leads to health inequalities, mainly through the cumulative disadvantage of the pressure conduction process (see Table 5 for detailed data).

Table 5 Decomposition of the channel effect of early life adversity on health ( $N=9701)$

\begin{tabular}{|c|c|c|c|c|c|c|}
\hline & \multicolumn{3}{|c|}{ Type of early life adversity } & \multicolumn{3}{|c|}{ Duration of early life adversity } \\
\hline & & Robust & Mediating effect & & Robust & Mediating effect \\
\hline & Estimate & SE & $\%$ & Estimate & SE & $\%$ \\
\hline \multicolumn{7}{|c|}{ Early life adversity } \\
\hline Total effect & $0.277^{* * *}$ & 0.023 & & $0.146^{* * *}$ & 0.024 & \\
\hline Direct effect & $0.081^{* * *}$ & 0.024 & & 0.031 & 0.024 & \\
\hline Indirect effect & $0.196^{* * *}$ & 0.047 & 70.76 & $0.115^{* *}$ & 0.049 & 78.77 \\
\hline \multicolumn{7}{|c|}{ Serious illness in early life } \\
\hline Total effect & $0.255^{* * *}$ & 0.021 & & $0.133^{* * *}$ & 0.022 & \\
\hline Direct effect & $0.245^{* * *}$ & 0.021 & & $0.127^{* * *}$ & 0.022 & \\
\hline Indirect effect & $0.010^{*}$ & 0.005 & 3.92 & 0.006 & 0.006 & 4.51 \\
\hline \multicolumn{7}{|c|}{ Self-rated poor health in early life } \\
\hline Total effect & $0.254^{* * *}$ & 0.021 & & $0.132^{* * *}$ & 0.022 & \\
\hline Direct effect & $0.230^{* * *}$ & 0.022 & & $0.120^{* * *}$ & 0.022 & \\
\hline Indirect effect & $0.023^{* * *}$ & 0.008 & 9.06 & 0.012 & 0.009 & 9.09 \\
\hline \multicolumn{7}{|l|}{ Education } \\
\hline Total effect & $0.256^{* * *}$ & 0.021 & & $0.134^{* * *}$ & 0.022 & \\
\hline Direct effect & $0.234^{* * *}$ & 0.022 & & $0.115^{* * *}$ & 0.022 & \\
\hline Indirect effect & $0.022^{* *}$ & 0.009 & 8.59 & $0.019^{*}$ & 0.01 & 14.18 \\
\hline \multicolumn{7}{|c|}{ Non-agricultural employment } \\
\hline Total effect & $0.257^{* * *}$ & 0.021 & & $0.134^{* * *}$ & 0.022 & \\
\hline Direct effect & $0.246^{* * *}$ & 0.021 & & $0.122^{* * *}$ & 0.022 & \\
\hline Indirect effect & 0.011 & 0.010 & 4.28 & 0.011 & 0.01 & 8.21 \\
\hline \multicolumn{7}{|l|}{ Residence place } \\
\hline Total effect & $0.258^{* * *}$ & 0.021 & & $0.135^{* * *}$ & 0.022 & \\
\hline Direct effect & $0.243^{* * *}$ & 0.021 & & $0.124^{* * *}$ & 0.022 & \\
\hline Indirect effect & 0.015 & 0.011 & 5.81 & 0.011 & 0.011 & 8.2 \\
\hline \multicolumn{7}{|c|}{ Relative economic status } \\
\hline Total effect & $0.259^{* * *}$ & 0.021 & & $0.135^{* * *}$ & 0.022 & \\
\hline Direct effect & $0.221^{* * *}$ & 0.022 & & $0.114^{* * *}$ & 0.022 & \\
\hline Indirect effect & $0.038^{* *}$ & 0.019 & 14.67 & 0.021 & 0.02 & 15.56 \\
\hline \multicolumn{7}{|l|}{ Disability risk } \\
\hline Total effect & $0.260^{* * *}$ & 0.022 & & $0.138^{* * *}$ & 0.022 & \\
\hline Direct effect & $0.239^{* * *}$ & 0.022 & & $0.127^{* * *}$ & 0.022 & \\
\hline Indirect effect & 0.021 & 0.019 & 8.08 & 0.011 & 0.019 & 7.97 \\
\hline \multicolumn{7}{|c|}{ Depressed emotions } \\
\hline Total effect & $0.273^{* * *}$ & 0.023 & & $0.143^{* * *}$ & 0.024 & \\
\hline Direct effect & $0.129^{* * *}$ & 0.023 & & $0.058^{* *}$ & 0.024 & \\
\hline Indirect effect & $0.144^{* * *}$ & 0.041 & 52.75 & $0.085^{* *}$ & 0.043 & 59.44 \\
\hline
\end{tabular}


For example, 70.76 percent of the effects that the cumulative types of early life adversities have on health is achieved by mediated variables, while the channel effect of the cumulative duration of starvation in early life is 78.77 percent.

We introduced four sets of mediating variables. First, the two factors of serious illness in early life and self-rated poor health in early life explain 11.42 percent of the effects of the cumulative types of early life adversities on health. Among them, self-rated poor health in early life explains approximately 9.06 percent. The channeling effect of the duration of starvation also shows similar characteristics, but it is not statistically significant. The accessibility of health resources based on personal development plays an important role in explaining the impact of early life adversity on health. The estimation results show that personal development factors explain 23.66 percent of the cumulative effects of the types of early life adversities on health and explain 30.91 percent of the cumulative effects of the duration of starvation in early life on health. Among them, the explanatory power of relative economic status is relatively strong, which explains 14.67 percent of the type of early life adversity and 15.56 percent of the duration of starvation, but the latter is not statistically significant. Second, the explanatory power of education explains 8.59 percent of the type of early life adversity and 14.18 percent of the duration of starvation. Early life adversity leads to development interference in people's life course, especially access to education and the promotion of social and economic status, which affects the accessibility of health resources in adulthood. The explanatory powers of non-agricultural employment, residence level, and disability risk on the health effects of early life adversity are not statistically significant. The last set of mediated variables is that of negative emotions. The estimation results show that depressive emotion explains 52.75 percent of the cumulative effects of the types of early life adversities on health and 59.44 percent of the cumulative effects of the duration of starvation on health, both of which are statistically significant. It can be seen that depression is the most important explanatory variable for the impact of early life adversity on health.

\section{Conclusion}

Taking time seriously, in this article, we address the question of whether there is a causal relationship between early life adversity and adulthood health. The results consistently show that there is a significant causal impact of early life adversity on poor health. An individual's life course often consists of a series of orderly, purposeful, and cumulative events and experiences along the time axis, and this individual's adulthood health is an outcome of the series of favorable and unfavorable events and experiences accumulated through the life course. While current research has largely focused on recent risk factors in explaining people's poor health, it is also important to study the early stages of life and how they affect people's health later in life (see also Ferraro et al. 2016).

If early life adversity does lead to poor health in adulthood, what is the underlying mechanism? This study shows that health, as a form of capital in life, is maintained or consumed over time by resources, strategies, and opportunities during life. Not only does early life adversity have a direct effect on an individual's health, but throughout the life course, it also produces cumulative disadvantages by 
worsening the individual's life conditions such as less education, lower socialeconomic status, and less job security. The combination of the counts of adversity experience and the length of exposure creates an exponential effect on individuals' poor health. The dual interaction between the counts and the duration of early life adversity contributes to the persistence of health inequality in contemporary Chinese society.

In addition, this study also finds that even when people experience social mobility upward, the health risks associated with early life adversity persist and are generally not offset by other positive or negative factors that accumulate. The early life experience and conditions reflect the characteristics of the original family, which reflect the social and economic status and lifestyle of the parents. Influenced by genetic inheritance and family environment, people's health endowments are differentiated in the early stages of life (Ferraro and Shippee 2009). On one hand, genetic inheritance from their parents determine adults' health endowments and their ability to resist health risks; on the other hand, adversity or stress in early life can cause disease in vivo and in a sufficiently lasting way for decades (Miller et al. 2011).

This article yields two major contributions. On the theoretical level, it puts forward a dual cumulative disadvantage hypothesis, which divides the cumulative disadvantage process into the cumulative stress of early adversity events and the cumulative process of stress conduction in adulthood as the internal mechanisms underlying the durable impact of early life adversity on individual health. At the empirical level, this article investigates the effects of both the counts/frequency and the duration of early life adversity events on people's health. It considers how variables, including health status in early life, education, and social status, might mediate how early life adversity could lead to health inequality through the life course.

This study provides a variety of perspectives for the adjustment and improvement of public policy. The first is the family perspective. The failure of families to perform their normal functions in the early life period is the root cause of various social problems, such as illness, unemployment, and poverty. In the context of the gradual weakening of family function in China, the family should be taken as the basic unit in the formulation, implementation, and evaluation of public policy, and enhancing family developmental ability should be regarded as an important goal in the formulation of public policy. The second is the process perspective. The aim of public policy should be on how to break the cumulative process of disadvantage caused by adversity or structural inequalities in early life and how to strengthen the attention given to the needs of families and the growth of children. The third and last is the upstream perspective. Many social problems, including health inequality, should be prevented and cured at the source of risk. The most effective and operational way to protect children is to provide family support that aims at prevention and early intervention, to help families improve their family relations, to help parents achieve a balance between their work and family responsibilities, to ensure family stability, and to enhance family functions. 


\section{Appendix}

Table 6 Moderating effects of education and socioeconomic status on the health effects of early life adversity

\begin{tabular}{|c|c|c|c|c|}
\hline & \multicolumn{2}{|l|}{+ Education } & \multicolumn{2}{|c|}{+ Socioeconomic status } \\
\hline & (1) Frequencies & (2) Duration & (3) Frequencies & (4) Duration \\
\hline \multirow[t]{2}{*}{ Type of early life adversity } & $0.236^{* * *}$ & & $0.210^{* * *}$ & \\
\hline & $(0.023)$ & & $(0.023)$ & \\
\hline \multirow[t]{2}{*}{ Duration of early life starvation } & & $0.123^{* * *}$ & & $0.109 * * *$ \\
\hline & & $(0.023)$ & & $(0.024)$ \\
\hline \multirow[t]{2}{*}{ Years of education } & $-0.038^{* * *}$ & $-0.044^{* * *}$ & & \\
\hline & $(0.007)$ & $(0.007)$ & & \\
\hline \multirow[t]{2}{*}{ Relative socioeconomic status } & & & $-0.398^{* * *}$ & $-0.422^{* * *}$ \\
\hline & & & $(0.029)$ & $(0.029)$ \\
\hline Type of early life adversity & $0.009^{*}$ & & & \\
\hline \#Years of education & $(0.005)$ & & & \\
\hline Duration of early life starvation & & $0.012^{* *}$ & & \\
\hline \#Years of education & & $(0.005)$ & & \\
\hline Type of early life adversity & & & -0.011 & \\
\hline \#Relative socioeconomic status & & & $(0.025)$ & \\
\hline Duration of early life starvation & & & & -0.004 \\
\hline \#Relative socioeconomic status & & & & $(0.026)$ \\
\hline Control variables & Y & Y & Y & Y \\
\hline$N$ & 9701 & 9701 & 9701 & 9701 \\
\hline$R^{2}$ & 0.048 & 0.041 & 0.063 & 0.057 \\
\hline
\end{tabular}

Robust standard errors are in parentheses.

The number of early life adversity, duration of starvation, years of schooling, and socioeconomic status were all addressed in the mode.

The control variables include the original family characteristics, the initial health endowment, the demographic characteristics, and the provincial dummy variables

${ }^{*} p<0.1$

${ }^{* *} p<0.05$

${ }^{* * *} p<0.01$

\section{Acknowledgements}

N/A

Authors' contributions

Zhilei Shi designed the study and conducted research; Cary Wu contributed in analysis and modeling. The author(s) read and approved the final manuscript.

Funding

This study was supported by the National Social Science Fund of China (NO.19ARK004).

Availability of data and materials

We based our study on data, publicly available of the China Health and Retirement Longitudinal Survey (CHARLS, 2011-2014).

Competing interests

The authors declare they have no competing interests.

\section{Author details}

${ }^{1}$ Research Center of Population and Health, Zhongnan University of Economic and Law, 182\# Nanhu Avenue, East Lake High-tech Development Zone, Wuhan 430073, People's Republic of China. ${ }^{2}$ Department of Sociology, York University, 4700 Keele Street, Toronto M3J 1P3, Canada. 
Received: 8 March 2020 Accepted: 26 May 2020

Published online: 06 July 2020

\section{References}

Adams, Peter, Michael D. Hurd, Daniel McFadden, Angela Merrill, and Tiago Ribeiro. 2003. Healthy, wealthy, and wise? Tests for direct causal paths between health and social economic status. Journal of Econometrics 112 (1): 3-56.

Baert, Patrick. 1992. Time, self and social being temporal with China social logical context. Newcastle: Athenaeum Press.

Barker, David. 1990. The fetal and infant origins of adult disease. British Medical Journal 301 (6761): 1111.

Barker, David. 1998. Mothers, babies and health in later life. Public Health 113 (5): 14-36.

Berg, Gerard, Pia R. Pinger, and Johannes Schoch. 2016. Instrumental variable estimation of the causal effect of hunger early in life on health later in life. The Economic Journal 126 (591): 465-506.

Blackwell, Debra, Mark D. Hayward, and Eileen MCrimmins. 2001. Does childhood health affect chronic morbidity in later life? Social Science and Medicine 52 (8): 1269-1284.

Chen, Jingqi. 2006. Research on child abuse and victimized children's mental health in China. Chinese Journal of Pediatrics 8: $625-628$.

Cohen, Sheldon, Kessler Ronald, and Gordon Lynn Underwood. 1995. Strategies for measuring stress in studies of psychiatric and physical disorders. In Measuring stress: a guide for health and social scientists, ed. S. Cohen, R.C. Kessler, and G.L. Underwood. New York: Oxford University Press.

Currie, Janet. 2011. Inequality at birth: some cause and consequences. American Economic Review 3: 1-22.

Dannefer, Dale. 2003. Cumulative advantage/disadvantage and the life course: cross-fertilizing age and social science theory. The Journal of Gerontology Series B: Psychological Science and Social Sciences 58 (6): 327-337.

Diprete, Thomas, and Gregory M. Eirich. 2006. Cumulative advantage as a mechanism for inequality: a review of theory and empirical developments. Annual Review of Sociology 32: 271-297.

Dong, Maxia, Wayne H. Giles, Vincent J. Felitti, Shanta R. Dube, and Robert F. Anda. 2004. Insight into causal pathway for ischemic heart disease. Circulation 110 (13): 1761-1766.

Drukker, Marjan, Charles Kaplan, Frans Feron, and Jimvan Van Os. 2003. Children's health-related quality of life, neighborhood socio-economic deprivation and social capital. A Contextual Analysis. Social Science and Medicine 57 (5): 825-841.

Elder, H. Glen. 1998. The life courses development theory. Child Development 69 (1): 1-12.

Elo, Irma. 2009. Social class differentials in health and mortality: patterns and explanations in comparative perspective. Annual Review of Sociology 35: 553-572.

Evans, Gary, and Pilyoung Kim. 2007. Childhood poverty and health: cumulative risk exposure and stress dysregulation. Psychological Science 18 (11): 953-957.

Ferraro, Kenneth, and Jessica A. Kelley-Moore. 2003. Cumulative disadvantage and health: Iong-term consequence of obesity? American Sociological Review 68 (5): 7074-7729.

Ferraro, Kenneth, Markus H. Schafer, and Lindsay R. Wilkinson. 2016. Childhood disadvantage and health problem in middle and later life: early imprints on physical health? American Sociological Review 81 (1): 107-133.

Ferraro, Kenneth, and Tetyana Pylypiv Shippee. 2009. Aging and cumulative inequality: how does inequality get under the skin? The Gerontologist 49 (3): 333-343.

Ferrie, Jane, Martin J. Shipley, Stephen A. Stansfeld, George Davey Smith, and Michael Marmot. 2003. Future uncertainty and social economic inequalities in health: the whitehall II study. Social Science and Medicine 57 (4): 637-646.

Foucault, Michel. 2012. Discipline and punish: The birth of the prison. New York: Vintage Books.

Friedman, Esther, Jennifer Karas Montez, Connor McDevitt Sheehan, Tara L. Guenewald, and Teresa E. Seeman. 2015. Childhood adversities and adult cardiometabolic health: does the quantity, timing, and type of adversity matter? Journal of Aging and Health 27 (8): 1311-1338.

Frijters, Paul, and Aydogan Ulker. 2008. Robustness in health research: do differences in health measures, techniques, and time frame matter? Journal of Health Economics 27 (6): 1626-1644.

Fu, Qiang, Cary Wu, Heqing Liu, Zhilei Shi, and Gu Jiaxin. 2018. Live like mosquitoes: hukou, rural-urban disparity, and depression. Chinese Journal of Sociology 4: 56-78.

George, Linda. 2014. Taking time serious: a call to action in mental health research. Journal of Health and Social Behavior 55: 251-264.

Giddens, Anthony. 1984. The constitution of society: outline of the theory of structuration. Berkeley: University of California Press.

Goodwin, Renee, Christina W. Hoven, Robert Murison, and Robert Murison. 2003. Association between childhood physical abuse and gastrointestinal disorder and migraine in adulthood. American Journal of Public Health 93 (7): 1065-1067.

Greenfield, Emily, and Nadine F. Marks. 2009. Violence from parent in childhood and obesity in adulthood: using food response to stress as a mediator of risk. Social Science \& Medicine 68 (5): 791-798.

Grundy, Emily, and Andy Sloggett. 2003. Health inequalities in older population: the role of personal capital, social resources and socio-economic circumstances. Social Science \& Medicine 56 (5): 935-947.

Hu, Z., and Peng, X. 2015. Household changes in contemporary China: an analysis based on the four recent censuses. The Journal of Chinese Sociology. 2(1): 9.

Jiao, K. 2016. A study of the influential factors for health inequality. The Journal of Chinese Sociology 3(1): 5.

Jylha, Marja. 2009. What is self-rated health and why does it predict mortality? Towards a unified conceptual model. Social Science \& Medicine 69 (3): 307-316.

Kohler, U., Karlson, K. B., and Holm, A. 2011. Comparing coefficients of nested nonlinear probability models. The Stata Journal, 11 (3): $420-438$

Levine, Morgan, Cole Steven, Weir David, and Eileen Crimmins. 2015. Childhood and later life stressors and increased inflammatory gene expressions at older ages. Social Science \& Medicine 130: 16-22.

Lloyd, Donald, and John Taylor. 2006. Lifetime cumulative adversity, mental health and the risk of becoming a smoker. Health 10 (1): 95-112.

Lloyd, Donald, and Jay Turner. 2008. Cumulative lifetime adversities and alcohol dependence in adolescence and young adulthood. Drug and Alcohol Dependence 93 (3): 217-226. 
Mcdonough, Peggy, Amanda Sacker, and Richard D. Wiggins. 2005. Time on my side? Life course trajectories of poverty and health. Social Science \& Medicine 61 (8): 1795-1808.

McLanahan, S., Tach, L., and Schneider, D. 2013. The causal effects of father absence. Annual Review of Sociology 39: 399-427. Merton, Robert. 1968. The Matthew effective science. Science 159 (3810): 56-63.

Miller, Gregory E., Chen Edith, and Parker Karen. 2011. Psychological stress in childhood and susceptibility to the chronic diseases of aging: moving toward a model of behavioral and biological mechanisms. Psychological Bulletin 137 (6): 959.

Montez, Jennifer, and Mark D. Hayward. 2014. Cumulative childhood adversity, educational attainment, and active life expectancy among US adults. Demography 51 (2): 413-435.

Mu, Ren, and Xiaobo Zhang. 2011. What does the great Chinese famine affect the male and female survivors differently? Mortality Selection Versus Son Preference. Economics and Human Biology 9 (1): 92-105.

Pearlin, Leonard, Scott Schieman, Elena M. Fazio, and Stephen C. Meersman. 2005. Stress, Health, and the Life Course: Some Conceptual Perspectives. Journal of Health and Social Behavior 46 (2): 205-219.

Schafer, Markus, Kenneth F. Ferraro, and Sarah A. Mustillo. 2011. Children of adversity: early adversity and cumulative inequality in perceived life trajectories. American Journal of Sociology 116 (4): 1053-1091.

Schafer, Markus, Lindsay R. Wilkinson, and Kenneth F. Ferraro. 2013. Childhood (Mis) fortune, educational attainment, and adult health: contingent benefits of a college degree? Social Forces 91 (3): 1007-1034.

Sen, Amartya. 1981. Poverty and famines: an essay on entitlement and deprivation. Oxford: Oxford University Press.

Sen, Amartya. 1983. Poor, relatively speaking. Oxford Economic Papers 35 (2): 153-169.

Smith, George Davey, and John Morris. 1994. Increasing inequalities in the health of the nation: governmental action at last? British Medical Journal 309 (6967): 1994.

Sonderskov, Kim Mannemar, and Dinesen Peter Thisted. 2014. Danish exceptionalism: explaining the unique increase in social trust over the past 30 years. European Social Logical Review 30 (6): 782-795.

Turner, R. Jay, and Donald A. Lloyd. 1995. Lifetime traumas and mental health: the significance of cumulative adversity. Journal of Health and Social Behavior 36: 374-404.

Wang, Fuqin. 2011. Does social mobility contribute to reduce the inequality of health? Sociological Studies 2: 78-101.

Warren, J. Robert. 2016. Does growing childhood socioeconomic inequality mean future inequality in adult health? The Annals of the American Academy of Political and Social Science 663: 292-330.

Willson, Andrea, Kim M. Shuey, and Glen H. Elder. 2007. Cumulative advantage processes of inequality in life course health. American Journal of Sociology 112 (6): 1886-1924.

Xu, A., Zhang, J., and Xia, Y R. 2008. Impacts of parents' divorce on Chinese children: A model with academic performance as a mediator. Marriage \& Family Review 42(3): 91-119.

\section{Publisher's Note}

Springer Nature remains neutral with regard to jurisdictional claims in published maps and institutional affiliations.

\section{Submit your manuscript to a SpringerOpen ${ }^{\circ}$ journal and benefit from:}

- Convenient online submission

- Rigorous peer review

- Open access: articles freely available online

- High visibility within the field

- Retaining the copyright to your article

Submit your next manuscript at $\boldsymbol{\nabla}$ springeropen.com 